Volume 3, Issue 4 October-December 2018, Pages: 271, DOI: http://dx.doi.org/10.19082/ah271

\title{
MOLECULAR DOCKING OF CC2-PLA2, A PHOSPHOLIPASE A2-DERIVED FROM CERASTES CERASTES VENOM WITH ITS INHIBITORS
}

\author{
Chérifi Fatah, Saoud Samah and Laraba-Djebari Fatima*
}

*Tel: +21321336076; Fax: +21321336077, Email: flaraba@hotmail.com, flaraba@usthb.dz

USTHB, Faculty of Biological Sciences; Laboratory of Cellular and Molecular Biology, BP 32 El-Alia, Bab Ezzouar, Algiers, Algeria

\section{TYPE OF ARTICLE: CONFERENCE ABSTRACT}

\begin{abstract}
The current study reported a structure-based molecular docking of $\mathrm{Cc}_{2}-\mathrm{PLA}_{2}$, a phospholipase $\mathrm{A} 2$ purified from Cerastes cerastes venom by three chromatographic steps. Its molecular weight was equal to $13,534.16 \mathrm{Da}$ and its sequence identified by proteomic analysis consists of 120 amino acid residues. Structurally, when modeled by homology, $\mathrm{Cc}_{2}-\mathrm{PLA}_{2}$ 3D structure appeared organized into $2 \beta$-strands $(11 \%), 3 \alpha$-helices $(42 \%)$ and $11 \%$ disordered structure. To explore their inhibitory effect against $\mathrm{Cc}_{2}-\mathrm{PLA}_{2}$ enzymatic activity, curcumin and its analogs, derived from chemical modification of curcumin, were submitted to a molecular docking study. Our results show that all of the curcumin, tetrahydrocurcumin and dihydrocurcumin interact with $\mathrm{Cc}_{2}-\mathrm{PLA}_{2}$ by a hydrogen bond established with $\mathrm{His}^{47}$. Moreover, hexahydrocurcumin targeted the residue $\mathrm{Asp}^{48}$ of $\mathrm{Cc}_{2}-\mathrm{PLA}_{2}$. Besides this, among all compounds, the most potent complexes were established with hexahydrocurcumin and tetrahdrocurcumin as they show the most negative energies of interaction. This result shows that chemical modification of curcumin promoted its affinity to $\mathrm{Cc}_{2}-\mathrm{PLA}_{2}$ and therefore, potentiates the inhibitory effect. $\mathrm{His}^{47}$ and $\mathrm{Asp}^{48}$ being involved in the catalytic loop of $\mathrm{Cc}_{2}-\mathrm{PLA}_{2}$ thus reinforce the obtained results and confirm the inhibitory effect of the studied compounds against the catalytic activity of our enzyme on its specific substrates. The current study opens perspectives for the design of new snake venom-phospholipase A2 inhibitors and the improvement of envenomation therapy.
\end{abstract}

KEYWORDS: Phospholipase A2, 3D modeling, Curcumin, Inhibition, Docking

\footnotetext{
Abstracts of Third International Conference on Health Sciences and Medical Technologies, October 2018, Tlemcen, Algeria (ICHSMT-18)

(C) 2018 The Authors. This is an open access article under the terms of the Creative Commons Attribution-NonCommercialNoDerivs License, which permits use and distribution in any medium, provided the original work is properly cited, the use is non-commercial and no modifications or adaptations are made.
} 